\title{
Food Insecurity, Prenatal Care and Other Anemia Determinants in Pregnant Women from the NISAMI Cohort, Brazil: Hierarchical Model Concept
}

\section{Insegurança alimentar, cuidado pré-natal e outros determinantes da anemia em mulheres grávidas da coorte Nisami, Brasil: modelo conceitual hierárquico}

\author{
Fran Demétrio ${ }^{1}$ Carlos Antônio de Souza Teles-Santos ${ }^{2,3}$ Djanilson Barbosa dos Santos ${ }^{1}$ \\ ${ }^{1}$ Centro de Ciências da Saúde, Universidade Federal do Recôncavo da \\ Bahia, Santo Antônio de Jesus, BA, Brazil \\ 2 Instituto de Saúde Coletiva, Universidade Federal da Bahia, Salvador, \\ BA, Brazil \\ ${ }^{3}$ Biostatistics and Molecular Epidemiology Laboratory, Centro de

\begin{abstract}
Address for correspondence Fran Demétrio, PhD, Centro de Ciências da Saúde, Universidade Federal do Recôncavo da Bahia, Av. Carlos Amaral, $n^{\circ}$ 1015, Cajueiro, 44570-000 - Santo Antônio de Jesus, BA, Brazil (e-mail: frandemetrio7@gmail.com; fdemetrio@ufrb.edu.br).
\end{abstract} Pesquisas Gonçalo Moniz-Fiocruz, Salvador, BA, Brazil

Rev Bras Ginecol Obstet 2017;39:384-396.

\begin{abstract}
Keywords

- women's health

- pregnant women

- anemia

- prenatal care

- food and nutrition security

Objective To identify the prevalence of anemia and its relation to food insecurity (FI) and other determinants in pregnant women.

Methods A cross-sectional, cohort-nested study, with the participation of 245 pregnant women who were cared for at Family Health Units in the municipality of Santo Antônio de Jesus, Bahia, Brazil. The participants underwent blood tests for hemoglobin levels, anthropometric examinations, and answered a structured questionnaire. The hemoglobin $(\mathrm{Hb})$ parameter $(\mathrm{Hb}<11 \mathrm{~g} / \mathrm{dL})$ was used for the classification of the diagnosis of anemia. Food insecurity was evaluated using the North American short-scale food insecurity assessment. Logistic regression was adopted for the statistical analyses, based on a hierarchical conceptual model that enabled the measurement of the decomposition of the total effect of its non-mediated and mediated components using the proposed hierarchical levels.

Results The prevalence of anemia in the studied population was of $21.8 \%$, and the average hemoglobin was $12.06 \mathrm{~g} / \mathrm{dL}$ (standard deviation [SD]: 1.27). Food insecurity was identified in $28.16 \%$ of the pregnant women. The average maternal age was 25.82 years (SD: 5.94). After ranking, the variables positively associated with anemia remained significant: $\mathrm{Fl}$ (odds ratio $[\mathrm{OR}]=3.63 ; 95 \%$ confidence interval $[95 \% \mathrm{Cl}]$ : $1.77-7.45$ ); not undergoing prenatal care $(\mathrm{OR}=5.15 ; 95 \% \mathrm{Cl}: 1.43-18.50)$; multiparity $(\mathrm{OR}=2.27 ; 95 \% \mathrm{Cl}$ : 1.02-5.05); and non-supplementation of iron medication ( $\mathrm{OR}=2.45$; $95 \% \mathrm{Cl}: 1.04-5.76)$. The results also indicated that the socioeconomic and environmental factors were largely mediated by food insecurity and factors regarding prenatal care.
\end{abstract}

received

October 26, 2016

accepted

March 31, 2017

published online

June 30, 2017
Copyright @ 2017 by Thieme Revinter

Publicações Ltda, Rio de Janeiro, Brazil
License terms

(c) $(1) \$$
$10.1055 / \mathrm{s}-0037-1604093$. ISSN 0100-7203. 


\section{Resumo}

\section{Palavras-chave}

- saúde da mulher

- gestantes

- anemia

- cuidado pré-natal

- segurança alimentare nutricional
Conclusions In the present study, the chance of occurrence of anemia in pregnant women was significantly higher, mainly among women: in situations of food insecurity, not undergoing prenatal care, not having received iron supplements, and who are multiparous.

Objetivo Identificar a prevalência de anemia e sua relação com a insegurança alimentar (IA) e outros determinantes em mulheres grávidas.

Métodos Trata-se de estudo transversal aninhado a uma coorte, do qual participaram 245 gestantes atendidas em Unidades de Saúde da Família do município de Santo Antônio de Jesus-BA. As participantes foram submetidas a exame de sangue para dosagem de hemoglobina, exame antropométrico, e responderam a um questionário estruturado. Utilizou-se o parâmetro hemoglobina $(\mathrm{Hb}<11 \mathrm{~g} / \mathrm{dL})$ para a classificação do diagnóstico de anemia. A IA foi avaliada por meio da escala curta norte-americana de avaliação da segurança alimentar. Para as análises estatísticas, adotou-se a regressão logística, tomando-se como base um modelo conceitual hierarquizado definido a priori, que possibilitou a mensuração da decomposição do efeito total em seus componentes não mediados e mediados nos níveis hierárquicos propostos.

Resultados A prevalência de anemia na população estudada foi de $21,8 \%$, e a média de hemoglobina foi de $12,06 \mathrm{~g} / \mathrm{dL}$ (desvio padrão [DP]: 1,27). A IA foi identificada em $28,16 \%$ das gestantes. A média de idade materna foi de 25,82 anos (DP: 5,94 ). Após a hierarquização, permaneceram significativas as variáveis associadas positivamente à anemia: IA (razão de possibilidades $[O R]=3,63$; intervalo de confiança de $95 \%$ [IC95\%]: 1,77-7,45); não realização de pré-natal ( $O R=5,15$; IC95\%: 1,43-18,50); multiparidade ( $O R=2,27$; IC95\%: 1,02-5,05); e a não suplementação medicamentosa de ferro $(O R=2,45$; IC95\%: 1,04-5,76). Os resultados indicaram ainda que os fatores socioeconômicos e ambientais foram mediados em grande parte pela IA e pelos fatores de cuidado pré-natal.

Conclusões Nesse estudo, a chance de ocorrência de anemia em gestantes foi significantemente maior, principalmente, entre aquelas que estavam em situação de IA, não realizaram o pré-natal, eram multíparas, e não fizeram a suplementação de ferro.

\section{Introduction}

Gestation is a period of physiological vulnerability in the life of women, and it involves biological, physical and psychosocial changes. ${ }^{1}$ Accordingly, pregnant women form a priority group in the development of specific care, actions and policies by the public healthcare system involving not only the health of the woman-mother, but also the health of the fetus. ${ }^{2,3}$

Nevertheless, an elevated portion of women during the pregnancy-puerperal phase expresses high rates of anemia, even after the implementation of public health programs and policies with the aim of controlling this problem, namely during gestation. This can be observed, for example, with the medicinal iron supplementation treatment and the enrichment of wheat and corn flour, and the effectiveness of these actions should be discussed. ${ }^{4,5}$

Anemia is represented by a decrease in hemoglobin in the blood, and its main etiology is characterized by the abnormal biosynthesis of hemoglobin. Regarding this, iron-deficiency anemia and anemia of chronic disease (present in infectious, inflammatory or neoplastic processes) represent the most common types of iron metabolism disorders. Another type is anemia due to hemoglobinopathies. ${ }^{3,6}$

In accordance with the World Health Organization $(\mathrm{WHO})^{3}$ iron-deficiency anemia is the most prevalent nutritional deficiency condition in the world, and it mainly affects women of reproductive age, pregnant women and children. The global prevalence for this issue for pregnant women is estimated at $41.8 \%$, and at $29.1 \%$ for Brazil. ${ }^{3}$ During pregnancy, mainly in the 2nd and 3rd quarters, 4 to $5 \mathrm{mg}$ per day of iron is necessary to guarantee the balance of this nutrient. ${ }^{6}$

Iron-deficiency anemia is the result of an evolution due to successive stages of iron deficiency until the deficit of hemoglobin ${ }^{3}$ is installed. Accordingly, WHO suggests anemia as a proxy of iron-deficiency anemia, and the latter as an estimator of the general prevalence of iron deficiency in the populations of underdeveloped and developing countries that do not have any other important markers for anemia. ${ }^{3}$ Notwithstanding the importance of this proposal by the WHO for the formulation of strategies for the control of 
anemia in pregnant women, some surveys have signaled that the cases of anemia attributed to maternal iron deficiency were below what was expected, indicating the necessity of caution when using the prevalence of anemia as a proxy for iron-deficiency anemia and the latter as an iron deficiency estimator in pregnancy. ${ }^{3,4}$

The occurrence of anemia during pregnancy is associated to socio-environmental and economic conditions, prenatal care, behavioral aspects and nutritional factors, especially the anthropometric nutritional state and food consumption (namely dietary sources of iron or dietary sources that improve bioavailability). ${ }^{2,3,7}$

In accordance with Fischer et $\mathrm{al}^{8}{ }^{8}$ women of reproductive age and pregnant women present higher chances of developing anemia, mainly in the context of food insecurity (FI), which is marked by the decrease in quantity and quality of the food consumed. According to the results of the survey performed by these authors, the adjusted odds ratio (OR) for acquiring anemia was 31-43\% higher among women living under FI conditions.

It is understood that awareness of these factors could contribute toward the control of anemia during pregnancy, and mitigate the damages to the health and quality of life of the women and of the fetus, such as the occurrence of cardiac and immunological impairments, thus reducing maternal and perinatal mortality, prematurity and low birth weight. $2,3,6$

On the other hand, in Brazil there are few surveys that investigated the relationship between FI and the prevalence of anemia in pregnant women, above all when analyzed in conjunction with other determinants (socioeconomic, demographic, environmental, prenatal care, behavioral and nutritional determinants) and, primarily, established by means of a hierarchical conceptual model.

According to Teles-Santos, ${ }^{9}$ the hierarchical model could constitute an applicable alternative to the epidemiological studies with an elevated number of co-variables. Accordingly, the decision of including variables in a risk factor analysis for a certain outcome should not be exclusively based on statistical significance; it should also consider the hierarchical conceptual framework approach, which involves various levels. ${ }^{10}$ Thus, when investigating the factors associated to the genesis of cases of anemia during pregnancy, it is possible to determine input levels for the different variables, always when there is an interrelation among the variables at each level. ${ }^{10,11}$

For this purpose, assuming that anemia is not a nutritional or health condition determined only by biological factors, but involving also a set of socioeconomic, demographic, environmental, prenatal care and lifestyle determinants, among others, implies the consideration of the different levels of determination. ${ }^{11}$

In view of the exposed, the objective of this survey is to identify the prevalence of anemia and its relation to FI and other determinants in pregnant women, based on a hierarchical conceptual model that enables the measurement of the breakdown of the total effect in non-mediated components (or direct).

\section{Methods}

\section{Study Design}

A cross-sectional, cohort-nested study of pregnant women from the urban zone of the municipality of Santo Antônio de Jesus, Bahia, Brazil, performed between February 2014 and February 2015. The study integrated the more extensive survey entitled "Nutritional and Genetic Risk Factors during Gestation Associated to Low Birth Weight/Prematurity: the NISAMI cohort". a

The municipality of Santo Antônio de Jesus has a territorial area of $261 \mathrm{Km}^{2}$ and is located $187 \mathrm{Km}$ from the city of Salvador, the capital of the state of Bahia, Brazil. The municipality has 90,949 inhabitants, 79,271 of whom residing in the urban area, and 11,676 in the rural area, comprising 47,963 women and 42,986 men. ${ }^{12}$ It is considered the commercial and service hub of the south coast of Bahia (called Recôncavo in Portuguese). Most of the population of wage earners works in the local commerce. The human development index of the municipality is of 0.700 , and it occupies position 1,904 in the national rank of municipalities with the best human development index. ${ }^{13}$

A random sample of pregnant women aged between 14 and 49 years was selected between January and February 2014. The pregnant women were selected during prenatal consultations at the Family Health Unit (FHU) of the municipality. After this phase, an interview was scheduled (by phone) at the homes of the pregnant women for the application of the assessment scale for FI, which occurred between December and February 2015.

For effect of the sample power calculation of $80 \%$ for the sample of 245 pregnant women used in this study, we used a prevalence of anemia of $29.1 \%$, estimated by the $\mathrm{WHO}^{3}$ for Brazil, with a sample error of $8 \%$ and a reliability of $95 \%$.

\section{Selection Criteria}

Pregnant women with and without associated morbidities were included, but only those with anemia, diabetes (gestational or clinical) and arterial hypertension (gestational or clinical), residing in the urban zone of the municipality, adolescents and adults, with gestational ages of up to 32 weeks at the moment of the collection of information, and attending the prenatal care service at the FHU of the investigated municipality were selected. Those with multiple gestations, or with health issues such as pre-eclampsia, renal problems or HIV were not included in the survey. Therefore, these conditions were not identified among the selected pregnant women.

\section{Conceptual Model}

For the study of the determinants of anemia, the hierarchical conceptual model was established (-Fig. 1), which encompassed the factors organized hierarchically in 3 levels according to the proximal-intermediary-distal relation for the outcome under consideration (anemia). This strategy enabled the measurement of the breakdown of the non-

\footnotetext{
a Cohort financed by Conselho Nacional de Desenvolvimento Científico e Tecnológico (CNPq), process 481509/2012-7/ 2013. NISAMI (Núcleo de Investigação em Saúde Materno-Infantil/UFRB).
} 


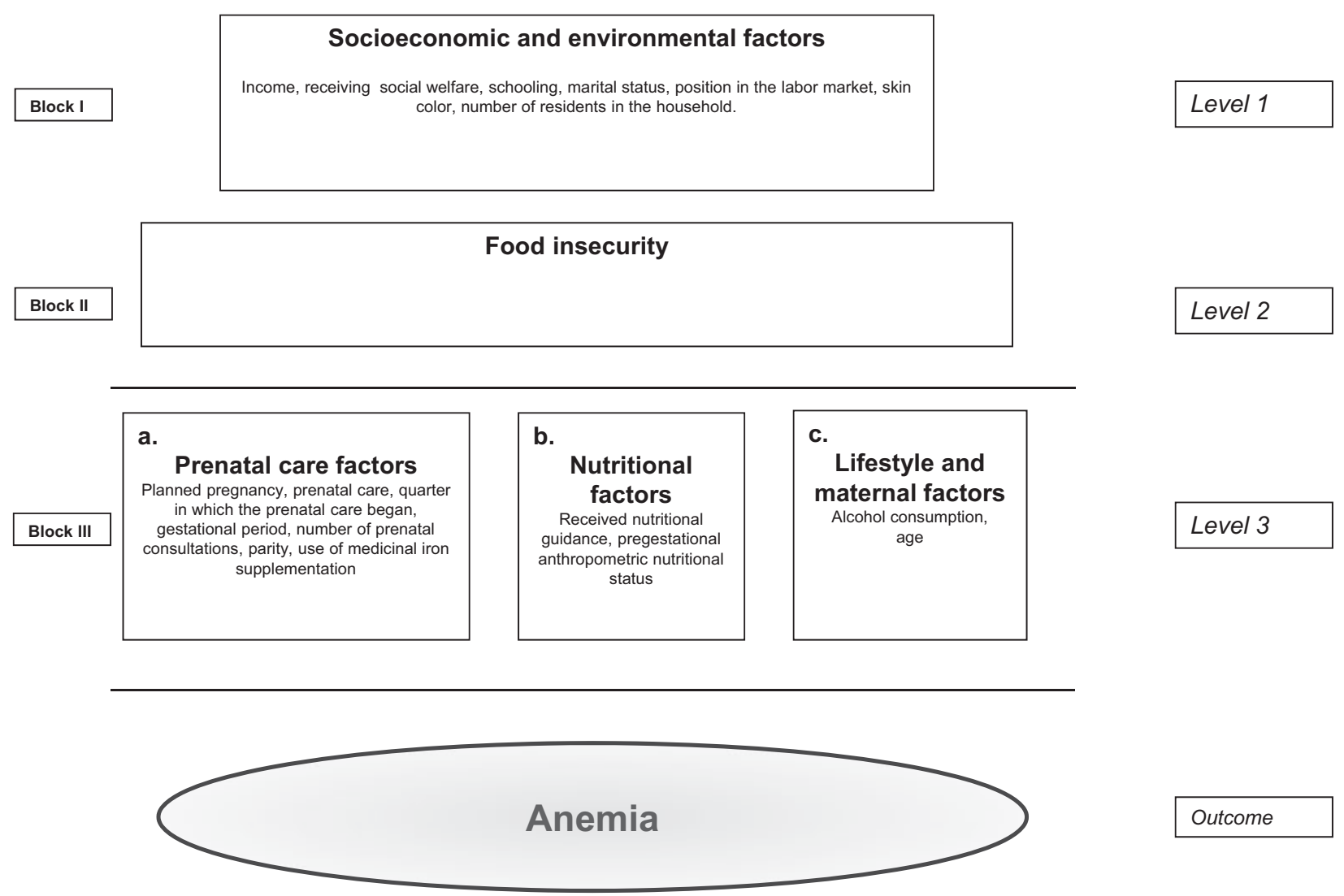

Fig. 1 Hierarchical conceptual model of the determinants of anemia in pregnant women.

mediated total (or direct) effect, as well as the study of the mediated (or indirect) effect in the proposed hierarchical levels. $^{10,14}$

\section{Variables of the Study}

A structured questionnaire was used to obtain information related to the socioeconomic, demographic, biological, environmental and prenatal care conditions. This questionnaire was applied by a previously trained team composed of nutritionists and nutrition students.

The independent variables are represented by socioeconomic and environmental factors, food insecurity, and prenatal care variables such as: age, gestational age, number of prenatal consultations, folic acid and ferrous sulfate supplementation, guidance during prenatal care, pregestational anthropometric nutritional status, lifestyle, and maternal lifestyle and age. The pregestational weight was obtained from the file of the pregnant woman, and when it was not available, the referred weight was registered. The height of the pregnant woman was verified by previously trained researchers and students of the Nutrition Course of one of our institutions. To verify the height, a Welmy stadiometer (Welmy, Santa Bárbara d'Oeste, SP, Brazil) with a capacity for $2,000 \mathrm{~mm}$ and sensitivity of $0.5 \mathrm{~cm}$ was used. The measurements were taken in duplicity. A maximum variation of $0.5 \mathrm{~cm}$ was accepted for the measurement of the length. ${ }^{15}$ The pregestational body mass index (BMI) was used as proxy variable of the maternal pregestational anthropometric nutritional status. This was classified based on the parameters of the Institute of Medicine (IoM), ${ }^{16}$ namely: low weight (BMI $<18.5$ ), adequate weight (BMI $=18.5$ to 24.9), and excess weight - overweight/obesity $(B M I \geq 25)$. Food insecurity was evaluated by means of the short version of the United States Department of Agriculture (USDA) ${ }^{12}$ Food Security Scale, which includes 6 questions related to food in the 12 months prior to the interview. This scale generates a score that ranges from 0 to 6 (- Table 1). ${ }^{12,17}$ In four questions, each positive answer corresponds to one point, while in one of the questions the point is given to a negative answer and, in another one, it corresponds to the time of exposure in which there was a decrease in the quantity of food due to lack of money. The score is calculated from the sum of these points. Food safety is considered for those pregnant women who score one point; food insecurity is considered for pregnant women scoring two to four points, and hunger is considered for those with a score of five to six points. ${ }^{12}$ The short scale was chosen due to the fact that it comprises a greater time interval in relation to the period of application (the last twelve months prior to the interview). In the present study, the scale was applied at the end of the gestations, between December and February 2015, with the purpose of identifying food insecurity situations in the households of the pregnant women. It should be observed that this scale was validated in a study conducted by Demétrio ${ }^{18}$ in households with pregnant women. The variables were categorized in a dichotomous manner in the descriptive analysis and in the hierarchized model. 
Table 1 Indicators (items) of the short version of the North American Food Security Assessment Scale

\begin{tabular}{l}
\hline Questions \\
\hline Item 1. During the past twelve months, did the food in your house finish and you had no money to buy more? \\
\hline Item 2. During the past twelve months, could you offer varied food to your family, with beans, rice, meat, salad and fruit? \\
\hline $\begin{array}{l}\text { Item 3. During the past twelve months, did you or any other member of your household have to decrease the quantity of } \\
\text { food or not have a meal for lack of money to buy more food? }\end{array}$ \\
\hline Item 4. In how many months did this occur? \\
\hline $\begin{array}{l}\text { Item } 5 \text {. During the past twelve months, did you eat less than you would wish to because you had no money to buy } \\
\text { more food? }\end{array}$ \\
Item 6. During the past twelve months, did you feel hungry but did not eat because you had no money to buy more food? \\
Source: Bickel et al, ${ }^{12}$ Santos et al. ${ }^{17}$
\end{tabular}

The dependent variable was represented by anemia, which was categorized as follows: without anemia $(\mathrm{Hb}>11 \mathrm{~g} / \mathrm{dL})-$ no $(0)$, with anemia $(\mathrm{Hb}<11 \mathrm{~g} / \mathrm{dL})$ - yes. Information on the concentration of hemoglobin was obtained by means of blood collection and analysis performed in a single laboratory that is certified by the Brazilian Public Healthcare System (SUS, in the Portuguese acronym) in the municipality of Santo Antônio de Jesus, which provides care to pregnant women assisted by the FHU. This laboratory is equipped with appropriate material and equipment for collecting and processing the samples, and it has a specialized team responsible for standardizing the processing procedures and biosecurity of the blood samples in order to perform the blood count and other prenatal exams. The hemoglobin concentration was obtained by means of a direct cyanmethemoglobin technique.

The gestational age was calculated based on the last menstruation date available on the record of the pregnant woman of the first ultrasound performed up until the end of the first gestational quarter.

\section{Statistical Analysis}

In the bivariate and multivariate analyses in a hierarchical theoretical model, the dependent variable (anemia) was modeled by means of the application of the logistic regression model. This model also enables the estimation of the odds ratio (OR), with the respective $95 \%$ confidence intervals (95\%CI), when comparing the exposed group to the group of reference of the specific determinant. In this study, a considerable increase in the value of the overestimation factor of the measure of the outcome was identified with the use of OR in comparison to the PR estimates.

In the bivariate analysis, the missing data was inserted and attributed the modal value, as proposed by Twisk. ${ }^{19}$

Intra-block multivariate analyses were applied to select the variables that would compose each one of the blocks in the hierarchized analysis, adopting the level of significance of $10 \%$ $(p \leq 0.10)$. Later, the hierarchized analysis was performed, which consisted of the adjustment of a sequence of models of logistic regression, including, a step-by-step, and blocks of possible determinants according to the pre-established conceptual model ( $\mathbf{- F i g}$. 1). Accordingly, it was possible to obtain estimates of the $\mathrm{OR}$, with its $95 \% \mathrm{CI}$, through the different models ( $\mathrm{A}, \mathrm{B}$ and $\mathrm{C}$ ), examining the possible paths through which the determinants would act. Model A (block I) estimated the total effect of the socioeconomic and environmental determinants. Model B (block II), included the determinants of the respective block, and estimated the effect of the socioeconomic determinants not mediated by the corresponding block. Models B and C (block III) estimated the effect of the socioeconomic and environmental determinants not mediated by the corresponding factors of the block (III.a) taken singly. Model E (Block III.a) estimated the effect of the socioeconomic and environmental determinants not mediated simultaneously by the determinants of block III.a, and the total effects of this block. Model D resulted from the adjustment by Model E. In the hierarchical analysis, the variables that remained associated to anemia were maintained, after control by the variables of confusion of the same level and for those hierarchically superior. ${ }^{17}$

The adjustment quality of the models was evaluated using the Akaike information criterion (AIC). This criterion was proposed by Akaike, ${ }^{20}$ and is defined as: $\mathrm{AIC}=-2 \ln (\mathrm{L})+2 \mathrm{p}$ and $\mathrm{BIC}=-2 \ln (\mathrm{l})+\operatorname{pln}(\mathrm{n})$, where $\mathrm{l}$ is the likelihood function; $\mathrm{n}$ is the number of observations; and $\mathrm{p}$ is the number of adjusted parameters.

The input of the information was performed using the EPIinfo software, version 6.04, and the statistical analyses were performed using the STATA for Mac (StataCorp, College Station, TX, US) software, version 12.0.

\section{Ethical Aspects}

The main project of which this study is a part of was evaluated and approved by the Ethics Committee in Research of one of our institutions under registration number 050/10.

\section{Results}

The maternal socio-environmental, economic, demographic, prenatal care, behavioral and nutritional characterization is presented in - Table 2.

A monthly family income between 2 and 4 minimum wages was identified in $52.65 \%$ of the women. Most of them (77.96\%) did not benefit from the Brazilian social welfare program called "Bolsa Família”; 80.00\% had spouses; $57.55 \%$ were unemployed; most had black skin color (87.76\%) and resided in households with 4 or more people (60.41\%). Total $71.84 \%$ of the households with pregnant women were in 
Table 2 Distribution of socio-demographic, environmental, prenatal care, lifestyle and nutritional maternal characteristics according to anemia during gestation; Santo Antônio de Jesus, Bahia. 2014-2015

\begin{tabular}{|c|c|c|c|c|c|c|c|}
\hline \multirow{3}{*}{$\begin{array}{l}\text { Variables } \\
(n=245)\end{array}$} & \multirow[t]{3}{*}{$\mathrm{n}$} & \multirow[t]{3}{*}{$\%$} & \multicolumn{4}{|c|}{ Anemia } & \multirow[t]{3}{*}{$p^{*}$} \\
\hline & & & \multicolumn{2}{|l|}{ No } & \multicolumn{2}{|c|}{ Yes } & \\
\hline & & & $\mathbf{n}$ & $\%$ & $\mathrm{n}$ & $\%$ & \\
\hline \multicolumn{8}{|l|}{ Block I } \\
\hline \multicolumn{7}{|c|}{ Family income (monthly income in minimum wages) } & 0.30 \\
\hline$<2$ & 51 & 20.82 & 36 & 70.59 & 15 & 29.41 & \\
\hline 2 to 4 & 129 & 52.65 & 103 & 79.84 & 26 & 20.16 & \\
\hline$\geq 5$ & 65 & 26.53 & 53 & 81.54 & 12 & 18.46 & \\
\hline \multicolumn{7}{|c|}{ Receiving social welfare (“Bolsa família” program) } & 0.21 \\
\hline Yes & 54 & 22.04 & 39 & 72.22 & 15 & 27.78 & \\
\hline No & 191 & 77.96 & 153 & 80.1 & 38 & 19.8 & \\
\hline \multicolumn{7}{|l|}{ Schooling (years) } & 0.83 \\
\hline 8 or more & 94 & 38.37 & 73 & 77.66 & 21 & 22.34 & \\
\hline Up to 7 & 151 & 61.63 & 119 & 78.81 & 32 & 21.19 & \\
\hline \multicolumn{7}{|l|}{ Marital status } & 0.12 \\
\hline With partner & 196 & 80.00 & 65 & 84.42 & 12 & 15.58 & \\
\hline Without partner & 49 & 20.00 & 127 & 75.60 & 41 & 24.40 & \\
\hline \multicolumn{7}{|c|}{ Position in the labor market } & 0.01 \\
\hline Working & 104 & 42.45 & 89 & 85.58 & 15 & 14.42 & \\
\hline Unemployed & 141 & 57.55 & 103 & 73.05 & 38 & 26.95 & \\
\hline \multicolumn{7}{|l|}{ Skin color } & 0.09 \\
\hline Not black & 30 & 12.24 & 27 & 90.00 & 3 & 10.00 & \\
\hline Black & 215 & 87.76 & 165 & 76.74 & 50 & 23.26 & \\
\hline \multicolumn{7}{|c|}{ Number of inhabitants in the household } & 0.02 \\
\hline$<4$ & 148 & 60.41 & 123 & 83.11 & 25 & 16.89 & \\
\hline$\geq 4$ & 97 & 39.59 & 69 & 71.13 & 28 & 28.87 & \\
\hline \multicolumn{8}{|l|}{ Block II } \\
\hline \multicolumn{7}{|l|}{ Food insecurity } & $<0.0001$ \\
\hline No & 176 & 71.84 & 150 & 85.23 & 26 & 14.77 & \\
\hline Yes & 69 & 28.16 & 42 & 60.87 & 27 & 39.13 & \\
\hline \multicolumn{8}{|l|}{ Block III } \\
\hline \multicolumn{8}{|l|}{ Block III.a } \\
\hline \multicolumn{7}{|l|}{ Planned pregnancy } & 0.07 \\
\hline Yes & 100 & 40.82 & 84 & 84.00 & 16 & 16.00 & \\
\hline No & 145 & 59.18 & 108 & 74.48 & 37 & 25.52 & \\
\hline \multicolumn{7}{|l|}{ Prenatal care } & $<0.01$ \\
\hline Yes & 187 & 76.33 & 154 & 82.35 & 33 & 17.65 & \\
\hline No & 58 & 23.67 & 38 & 65.52 & 20 & 34.48 & \\
\hline \multicolumn{7}{|c|}{ Quarter in which the prenatal care began } & 0.29 \\
\hline 1 & 43 & 17.55 & 30 & 69.77 & 13 & 30.23 & \\
\hline II & 189 & 77.14 & 151 & 79.89 & 38 & 20.11 & \\
\hline III & 13 & 5.31 & 11 & 84.62 & 2 & 15.38 & \\
\hline
\end{tabular}


Table 2 (Continued)

\begin{tabular}{|c|c|c|c|c|c|c|c|}
\hline \multirow{3}{*}{$\begin{array}{l}\text { Variables } \\
(n=245)\end{array}$} & \multirow[t]{3}{*}{ n } & \multirow[t]{3}{*}{$\%$} & \multicolumn{4}{|c|}{ Anemia } & \multirow[t]{3}{*}{$p^{*}$} \\
\hline & & & \multicolumn{2}{|l|}{ No } & \multicolumn{2}{|l|}{ Yes } & \\
\hline & & & $\mathrm{n}$ & $\%$ & $\mathrm{n}$ & $\%$ & \\
\hline \multicolumn{7}{|c|}{ Period of gestation (months) } & 0.38 \\
\hline I Quarter & 38 & 15.51 & 33 & 86.84 & 5 & 13.16 & \\
\hline II Quarter & 195 & 79.59 & 150 & 76.92 & 45 & 23.08 & \\
\hline III Quarter & 12 & 4.90 & 9 & 75.00 & 3 & 25.00 & \\
\hline \multicolumn{7}{|c|}{ Number of prenatal consultations } & 0.56 \\
\hline$<6$ & 5 & 2.04 & 3 & 60.00 & 2 & 40.00 & \\
\hline 6 to 9 & 42 & 17.14 & 34 & 80.95 & 8 & 19.05 & \\
\hline$\geq 10$ & 198 & 80.82 & 155 & 78.28 & 43 & 21.72 & \\
\hline \multicolumn{7}{|l|}{ Parity } & 0.04 \\
\hline Primipara & 109 & 44.49 & 92 & 84.4 & 17 & 15.6 & \\
\hline Multipara & 136 & 55.51 & 100 & 73.53 & 36 & 26.47 & \\
\hline \multicolumn{7}{|c|}{ Use of medicinal iron supplementation } & 0.02 \\
\hline Yes & 88 & 35.92 & 76 & 86.36 & 12 & 13.64 & \\
\hline No & 157 & 64.08 & 116 & 73.89 & 41 & 26.11 & \\
\hline \multicolumn{8}{|l|}{ Block III.b } \\
\hline \multicolumn{7}{|c|}{ Received prenatal nutritional guidance } & 0.13 \\
\hline Yes & 112 & 45.71 & 83 & 74.11 & 29 & 25.89 & \\
\hline No & 133 & 54.29 & 109 & 81.95 & 24 & 18.05 & \\
\hline \multicolumn{7}{|c|}{ Pregestational anthropometrical nutritional status } & 0.23 \\
\hline Low weight & 138 & 56.33 & 113 & 81.88 & 25 & 18.12 & \\
\hline Adequate & 22 & 8.98 & 14 & 63.64 & 8 & 36.36 & \\
\hline Excess weight & 85 & 34.69 & 65 & 76.47 & 20 & 23.53 & \\
\hline \multicolumn{8}{|l|}{ Block III.c } \\
\hline \multicolumn{7}{|c|}{ Alcohol consumption } & 0.18 \\
\hline No & 210 & 85.71 & 167 & 79.52 & 43 & 20.48 & \\
\hline Yes & 35 & 14.29 & 25 & 71.43 & 10 & 28.57 & \\
\hline \multicolumn{7}{|l|}{ Age (years) } & 0.12 \\
\hline$<18$ & 17 & 6.94 & 10 & 58.82 & 7 & 41.18 & \\
\hline 18 to 30 & 170 & 69.39 & 135 & 79.41 & 35 & 20.59 & \\
\hline$>30$ & 58 & 23.67 & 47 & 81.03 & 11 & 18.97 & \\
\hline
\end{tabular}

Note: *Chi-squared test.

situations of food security, and $28.16 \%$, in situations of food insecurity; of those, $24.48 \%$ were living in situations of food insecurity without hunger, and $3.68 \%$ were living in situations of food insecurity with hunger.

With reference to the characteristics related to prenatal care, most of the mothers: had not planned the pregnancy (59.18\%); underwent prenatal care (76.33\%); began prenatal care in the second quarter of gestation (77.14\%); were in the second quarter of gestation (79.59\%); attended 10 or more prenatal consultations ( $80.82 \%$ ); were multiparous (55.51\%); and reported the use of medicinal supplementation with ferrous sulfate $(64.08 \%)$.
Regarding the behavioral, nutritional and maternal characteristics, we identified that $85.71 \%$ of the women did not consume alcohol, and 54.29\% did not receive nutritional guidance during the prenatal care. Pregestational low weight and excess weight were identified in $56.33 \%$ and $34.69 \%$ of the participants respectively. The age of most of the participants (69.39\%) ranged from 18 to 30 years, and the average age was 25.82 years (SD: 5.94 ).

The prevalence of anemia in the studied population was of 21.8\% (95\%CI: 16.89-27.7), and the average Hb concentration was $12.06 \mathrm{~g} / \mathrm{dL}$ (SD: 1.27). In this study, pregnant women with levels of $\mathrm{Hb}<7.0 \mathrm{~g} / \mathrm{dL}$, or, in other words, with severe 
anemia, according to the classification criteria of the $\mathrm{WHO}{ }^{3}$ were not identified.

In the bivariate analysis (-Table $\mathbf{2}$ ), the results demonstrated that the prevalence of anemia, comparatively, was statistically higher among pregnant women that were unemployed $(p=0.01)$, lived in households with 4 or more people $(p<0.01)$, were multiparas $(p=0.04)$, did not make use of medicinal iron supplementation $(p=0.02)$, and were in a situation of food insecurity $(p<0.0001)$. The variables marital status, receiving nutritional guidance during prenatal care, alcohol consumption and age presented $p$-values significantly lower than $20 \%$, and were also selected to compose the multivariate hierarchized model. The variable for receiving social welfare ("Bolsa Família"), although not statistically significant $(p=0.21)$, was also selected for the hierarchized multivariate analysis, because it was considered a proxy variable of income and of the health promotion actions, ${ }^{21}$ of which the explanatory importance over the outcome at issue is theoretically well-established. ${ }^{2}$

- Table 3 presents the breakdown of the estimates of the total non-mediated (direct) and mediated effects of the determinants, which were obtained from the adjustment of the three models of regression, according to the previously

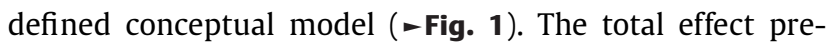
sented statistical significance for the determinants (models A, B and E). Thus, the total effect was statistically significant for the determinants of model A: marital status - without spouse $(p=0.09)$; position in the labor market - unemployed ( $p=0.03$ ); number of dwellers in the household $-\geq 4$ $(p=0.06)$; and maternal years of schooling - up to 7 $(p=0.37)$. Model B was statistically significant for food insecurity ( $p<0.0001)$. In model E, the variables associated to anemia in pregnant women remained statistically significant: food insecurity ( $p<0.0001)$; not undergoing prenatal care $(p=0.01)$; multiparity $(p=0.04)$; and lack of use of medicinal iron supplementation $(p=0.03)$. The variables for the labor market position, marital status, maternal schooling and age were incorporated and maintained in the final model, once these were known as potentially confounding in the studied relation.

Comparing the effects of the associations obtained using the three models, we observed, for example, that the measure of association of the determinants labor market position and the number of dwellers in the household presented substantial change after the adjustment by the variable of level 2 (model B). Then, comparing the labor market position and the number of dwellers in the household in relation to their respective groups of reference, the total effect was of 2.06 and 1.83 respectively (model A). The adjusted effect of the variable of level 2 (model B) was of 1.62 and 1.93 respectively. Therefore, we observed that the effects of the labor market position and the number of dwellers in the household in the determination of anemia among pregnant women were mediated by food insecurity. The same was observed in the adjustment of model $\mathrm{E}$, in which the socioeconomic and environmental factors were strongly mediated by prenatal care factors, with an emphasis on marital status (without spouse), which went from 1.95 (model b) to 0.78 (model E). Model D demonstrated that the factors related to prenatal care were the greatest mediators of socioeconomic and environmental factors in the determination of anemia in pregnant women (-Table $\mathbf{3}$ ).

\section{Discussion}

In the present investigation, the prevalence of anemia during gestation (21.8\%), in terms of magnitude, is a moderate public health issue, according to the WHO's ${ }^{3}$ criteria. The prevalence of anemia in pregnant women worldwide reduced from $52 \%$ to $41.8 \%$, a reduction of 19.6 percentage points. ${ }^{3}$

In accordance with the list of epidemiological information of the WHO (2008), ${ }^{3}$ comparatively, the prevalence of anemia in pregnant women identified in the present study is close to the estimated prevalence for Brazil (29.1\%) and other countries of the Americas (24.1\%), and lower than the prevalence identified in countries of Africa (57.1\%) and Southeast Asia (48.2\%). In turn, it was similar to the prevalence identified in other cross-sectional surveys conducted with pregnant women by Rocha et $\mathrm{al}^{22}$ (21.4\%) and Fujimori et $\mathrm{al}^{5}(20 \%)$, and higher than the prevalence found by Miglioli et $\mathrm{al}^{21}(16 \%)$ for the state of Pernambuco, and by Abriha et $\mathrm{al}^{23}(19.7 \%)$ for pregnant women from Mokelle, Ethiopia. Our prevalence rate was expressively lower than the one identified by Ferreira et $\mathrm{al}^{2}$ (50\%) for pregnant women from Alagoas, and by Khader et $\mathrm{al}^{24}$ (38.6\%) for Palestinian pregnant women, and it was the same as the one found by Murillo et $\mathrm{al}^{25}$ (21.8\%) for pregnant women cared for in public and private healthcare institutions in Cali, Colombia.

With regards to the epidemiological information on the prevalence of anemia among pregnant women in Brazil, the literature review study performed by Côrtes et $\mathrm{al}^{26}$ demonstrated that, since the 1970's, a large portion of the national surveys were conducted in the state of São Paulo, with results that classify the prevalence of anemia at moderate to severe epidemiological levels. According to the authors of this study, this situation could be even more worrying in socially and economically less developed states, in which the population has less access to healthcare services. In a certain manner, this fact corroborates the differences encountered in the prevalence of anemia for the different regions of Brazil.

Another aspect that has been discussed in the specific literature that may be related to these differences refers to different cut-off points for the diagnosis of anemia adopted in this survey. ${ }^{4}$ In accordance with Bresani et al, ${ }^{4}$ the choice of hematological parameters ( $\mathrm{Hb}$ and/or ferritin) and the cutoff points used for the diagnosis of anemia during pregnancy could be underestimating the iron deficiency and/or overestimating the occurrence of anemia.

In this study, the prevalence of anemia was significantly higher for pregnant women residing in households with more than four people. The investigation conducted with 150 pregnant women in the semi-arid region of Alagoas, Brazil, by Ferreira et $\mathrm{al}^{2}$ also identified this relationship.

The number of dwellers in the household was a variable of the structural level (level 1, block I), in accordance with the hierarchized conceptual model previously defined (-Fig. 1), 
392 Food Insecurity, Prenatal Care and Other Anemia Determinants Demétrio et al.

Table 3 Effect of the determinants of anemia in pregnant women according to different models. Santo Antônio de Jesus, Bahia. 2014-2015

\begin{tabular}{|c|c|c|c|c|c|}
\hline Variables & $\begin{array}{l}\text { Model A } \\
\left(^{(b l o c k ~ I) ~}\right.\end{array}$ & $\begin{array}{l}\text { Model B } \\
\text { (blocks I, II) }^{+}\end{array}$ & $\begin{array}{l}\text { Model C } \\
\text { (blocks I, II, III.a) }^{+}\end{array}$ & $\begin{array}{l}\text { Model D } \\
\text { (blocks I, II, III.a) }^{+}\end{array}$ & $\begin{array}{l}\text { Model E } \\
\text { (blocks I, II, III) }^{+}\end{array}$ \\
\hline \multicolumn{6}{|c|}{ Level 1-Block I: Socioeconomic and environmental factors } \\
\hline \multicolumn{6}{|l|}{ Marital status } \\
\hline With partner & 1 & 1 & & & 1 \\
\hline Without partner & $\frac{1.88}{(0.89-3.99)}$ & $\begin{array}{l}1.95 \\
(0.90-4.25)\end{array}$ & $\begin{array}{l}0.71 \\
(0.22-1.86)\end{array}$ & $\begin{array}{l}0.86 \\
(0.34-2.15)\end{array}$ & $\begin{array}{l}0.78 \\
(0.29-2.09)\end{array}$ \\
\hline \multicolumn{6}{|c|}{ Position in the labor market } \\
\hline Working & 1 & 1 & & & 1 \\
\hline Unemployed & $\frac{2.06}{(1.04-4.05)}$ & $\begin{array}{l}1.62 \\
(0.80-3.28)\end{array}$ & $\begin{array}{l}1.64 \\
(0.79-3.42)\end{array}$ & $\begin{array}{l}1.73 \\
(0.83-3.58)\end{array}$ & $\begin{array}{l}1.65 \\
(0.77-3.53)\end{array}$ \\
\hline \multicolumn{6}{|c|}{ Number of residents in the household } \\
\hline$<4$ & 1 & 1 & & & 1 \\
\hline$\geq 4$ & $\frac{1.83}{(0.97-3.43)}$ & $\begin{array}{l}1.93 \\
(1.01-3.70)\end{array}$ & $\begin{array}{l}2.31 \\
(1.15-4.64)\end{array}$ & $\begin{array}{l}2.25 \\
(1.13-4.48)\end{array}$ & $\begin{array}{l}1.97 \\
(0.95-4.09)\end{array}$ \\
\hline \multicolumn{6}{|l|}{ Schooling (years) } \\
\hline 8 or more & 1 & 1 & & & 1 \\
\hline Up to 7 & $\frac{1.35}{(0.69-2.63)}$ & $\begin{array}{l}1.40 \\
(0.70-2.80)\end{array}$ & $\begin{array}{l}0.38 \\
(0.12-1.14)\end{array}$ & $\begin{array}{l}0.38 \\
(0.12-1.16)\end{array}$ & $\begin{array}{l}0.36 \\
(0.11-1.15)\end{array}$ \\
\hline \multicolumn{6}{|l|}{ Level 2-Block II } \\
\hline \multicolumn{6}{|l|}{ Food insecurity } \\
\hline No & & 1 & & & 1 \\
\hline Yes & & $\frac{3.46}{(1.78-6.75)}$ & $\begin{array}{l}3.60 \\
(1.78-7.28)\end{array}$ & $\begin{array}{l}3.74 \\
(1.86-7.54)\end{array}$ & $\begin{array}{l}3.63 \\
(1.77-7.45)^{*}\end{array}$ \\
\hline \multicolumn{6}{|l|}{ Level 3-Block III } \\
\hline \multicolumn{6}{|c|}{ Block III.a. Prenatal care factors } \\
\hline \multicolumn{6}{|l|}{ Prenatal care } \\
\hline Yes & & & & & 1 \\
\hline No & & & $\begin{array}{l}5.98 \\
(1.74-20.52)\end{array}$ & $\begin{array}{l}5.15 \\
(1.52-17.36)\end{array}$ & $\frac{5.15}{(1.43-18.50)^{*}}$ \\
\hline \multicolumn{6}{|l|}{ Parity } \\
\hline Primipara & & & & & 1 \\
\hline Multipara & & & $\begin{array}{l}1.89 \\
(0.91-3.94)\end{array}$ & & $\frac{2.27}{(1.02-5.05)^{*}}$ \\
\hline \multicolumn{6}{|c|}{ Use of medicinal iron supplementation } \\
\hline Yes & & & & & 1 \\
\hline No & & & $\begin{array}{l}2.46 \\
(1.10-5.48)\end{array}$ & $\begin{array}{l}2.42 \\
(1.09-5.35)\end{array}$ & $\frac{2.45}{(1.04-5.76)^{*}}$ \\
\hline \multicolumn{6}{|c|}{ Block III.b. Nutritional Factors } \\
\hline \multicolumn{6}{|c|}{ Received nutritional prenatal guidance } \\
\hline Yes & & & & & 1 \\
\hline No & & & & & $\frac{0.64}{(0.31-1.33)}$ \\
\hline
\end{tabular}


Table 3 (Continued)

\begin{tabular}{|c|c|c|c|c|c|}
\hline Variables & $\begin{array}{l}\text { Model A } \\
\text { (block I) }^{+}\end{array}$ & $\begin{array}{l}\text { Model B } \\
\text { (blocks I, II) }^{+}\end{array}$ & $\begin{array}{l}\text { Model C } \\
\text { (blocks I, II, III.a) }^{+}\end{array}$ & $\begin{array}{l}\text { Model D } \\
\text { (blocks I, II, III.a) }^{+}\end{array}$ & $\begin{array}{l}\text { Model E } \\
\text { (blocks I, II, III)+ }\end{array}$ \\
\hline \multicolumn{6}{|c|}{ Block III.c. Lifestyle and maternal factors } \\
\hline \multicolumn{6}{|c|}{ Alcohol consumption } \\
\hline No & & & & & $\underline{1}$ \\
\hline Yes & & & & & $\frac{1.89}{(0.72-4.90)}$ \\
\hline \multicolumn{6}{|l|}{ Age (years) } \\
\hline$<18$ & & & & & $\frac{0.64}{(0.31-1.33)}$ \\
\hline 18 to 30 & & & & & $\underline{1}$ \\
\hline$>30$ & & & & & $\frac{0.38}{(0.91-1.62)}$ \\
\hline AIC & 253.46 & 242.08 & 231.21 & 232.22 & 234.53 \\
\hline
\end{tabular}

Abbreviations: ${ }^{+}$OR $(95 \% \mathrm{Cl})$; 95\%Cl, 95\% confidence interval; AIC, Akaike information criterion; OR, odds ratio.

Notes: In model B, the direct effect of the sociodemographic factors is observed (observe the change in OR in relation to model A) due to the mediation of the food insecurity factor. ${ }^{*}$ The same is observed in model E, with emphasis to the socioeconomic factors (marital status, with an alteration from 1.95 [model B] to 0.78 [model E], and maternal schooling [from 1.40 to 0.36 ]). With the adjustment of models $C$ and $D$ in relation to model $\mathrm{E}$, it is observed that the mediation was due to prenatal care factors.* The total effect of each factor is underlined (models $\mathrm{A}$, B and $\mathrm{E}$ ).

which was important in the explication of anemia in pregnant women, as it could be observed in the final and adjusted models. This is an important socio-environmental characteristic in the determination of anemia during pregnancy. This association was measured considering FI, and is explained, in part, by the reduction in the availability of food, in terms of quality and quantity, to the pregnant women, once the food available in the household is divided by a higher number of people.

The effect of the variable "number of dwellers in the household - more than four people" on the prevalence of anemia among pregnant women was even higher in the presence of factors related to prenatal care. This demonstrates the importance of prenatal care, which, under the influence of environmental factors, could contribute to family planning (respecting the right of the women to have children or not) and to a reduction in the occurrence of anemia during pregnancy.

In the present study, FI had a direct effect on the genesis of anemia among pregnant women. We also observed that, comparatively, the situation of FI represented a chance 2.63 times higher of the pregnant women developing anemia. This finding was close to the finding by Park and EicherMiller ${ }^{27}$ in a study conducted with pregnant women participating in the National Health and Nutrition Examination Survey (NHANES), in the United States. They identified a chance 3 times higher for the occurrence of anemia, mainly due to iron deficiency, among pregnant women in situations of FI, compared with those in situations of food security.

According to Fujimori et $\mathrm{al}^{28}$ in developing countries, eating habits do not adequately comply with the necessary quantity of bioavailable iron that must be consumed due to the high cost of red meat, which is considered the best source of heme iron, because it is better absorbed. The results of the surveys conducted by Schlindwein and Kassouf ${ }^{29}$ revealed that the standard consumption of meat among the Brazilian population is determined by the level of income and schooling of the women, and by the composition of the family. Therefore, pregnant women without spouses, who are unemployed, have low schooling, and live in households with more than four people and in situations of FI present greater chances of developing anemia.

The situation of FI is an important indicator of the inequalities created by the economic system. Poverty and social inequality are the main determinants of $\mathrm{FI}$, since they compromise mainly the access to proper food in terms of quantity and quality. Therefore, these factors may contribute, in a complementary manner, to the diagnosis of FI in households with pregnant women.

In the present study, the prevalence rate of FI (28.16\%) was lower than the rates identified by Marano et $\mathrm{al}^{30}$ (37.78\%) for pregnant women in two municipalities in the state of Rio de Janeiro, Brazil, and by Lôbo ${ }^{31}$ (59\%) for mothers from the city of João Pessoa, Brazil, and expressively higher than the prevalence found for North-American pregnant women (15.69\%) in the study by Park and Eicher-Miller. ${ }^{27}$ When compared with the data on the prevalence of FI produced by the Brazilian National Survey of Demography and Health of the Woman and Child (PNDS, in the Portuguese acronym), ${ }^{32}$ related to the year 2006, the prevalence of FI in this study was lower than the prevalence (38\%) identified for women (in the age group between 15 and 49 years of age) and their children (under 5 years of age). In relation to the data estimated by the 2013 Brazilian National Household Sample Survey (PNAD, in the Portuguese acronym), ${ }^{33}$ the prevalence rate found in the present study was lower than the estimated value for the Northeast region (38.1\%) and for the state of Bahia (37.2\%); 
nevertheless, it was higher than the percentage for Brazil as a whole (22.6\%) and for other regions of the country, in which the percentages were below $20 \%$.

It should be mentioned that, during the search for specific Brazilian literature on the prevalence of FI during pregnancy and its effects to the health and nutrition of the pregnant women, only the investigations conducted by Marano et $\mathrm{al}^{30}$ and Lôbo ${ }^{31}$ were identified with this approach.

The present study is the first to evaluate the effect of FI on anemia in pregnant women in Brazil as a whole. This reveals that the approach of FI during pregnancy is recent and scarce in Brazil, but some of the effects of its importance for the health of women have already been evidenced in the present and in other investigations; ${ }^{27,30,31}$ therefore, the results presented here, along with those from other well-conducted studies, should stimulate the development of further research in this direction.

In this study, the determinants related to prenatal care were those exercising greater mediating effect on the socioeconomic and environmental factors related to the genesis of anemia in pregnant women, with emphasis to marital status without spouse and lower maternal schooling. Such results are corroborated by those already found in other studies. ${ }^{28,34}$

If on the one hand these findings evidence that, apart from the biological condition favoring the development of anemia during pregnancy, ${ }^{11}$ it is not only reproduced, but also influenced, by structural conditions (distal), such as environmental conditions (number of dwellers in the household) and socioeconomic (position in the labor market, marital status and maternal schooling as variables of adjustment in the final hierarchized model), and intermediary (food insecurity). On the other hand, the relevance of the factors related to prenatal care is emphasized, which was considered, in the present investigation, as hierarchically proximal in the determination of anemia in pregnant women.

Among the prenatal care factors that integrate the conceptual model of the present study ( - Fig. 1), the non-realization of prenatal care, multiparity and the non-supplementation of iron demonstrated statistically significant associations with anemia in pregnant women.

Results from other studies with different models, ${ }^{7,35}$ nevertheless, also identified relationships between the non-realization of prenatal care and a greater occurrence of anemia during pregnancy. Ikeanyi and Ibrahim ${ }^{7}$ and Rezk et $\mathrm{al}^{35}$ encountered a greater chance of developing anemia among pregnant women who did not perform prenatal care; in their studies, the nonrealization of prenatal care increased, respectively, 130\% (OR $=2.30)$ and $25 \%(\mathrm{OR}=1.25)$ the chances that the pregnant women would develop anemia. In the study conducted by Szarfac et al $^{36}$ with pregnant women from São Paulo, the authors observed that prenatal care was associated to a higher concentration of $\mathrm{Hb}$ and lower occurrence of anemia during pregnancy.

The importance of prenatal care for the health of the pregnant woman and the fetus $\mathrm{s}^{36,37}$ is scientifically recognized. Thus, the Brazilian Ministry of Health recommends that prenatal care should begin at an early stage, offering universal coverage, and performed periodically and integrated with other curative actions and health promotion actions for the mother and the fetus, with at least six consultations. ${ }^{36,37}$ Clinical procedures that are essential for accompanying the pregnancy, such as laboratory exams, vaccines, educational activities and family planning, ${ }^{36,37}$ should also be included.

According to Rasia and Albernaz, ${ }^{37}$ notwithstanding the advances in relation to the increase in the coverage of prenatal care in Brazil, it is still possible to identify inequalities in the prenatal care offered to the pregnant women. Pregnant women with unfavorable socioeconomic situations, low schooling, and who reside in rural areas - factors associated to worse health and nutritional conditions continue to be the ones that seek prenatal care the less, which evidences the social and geographical inequality that is reflected in the precarious access to health services such as prenatal care, obeying the inverse care law. ${ }^{37}$

Apart from the epidemiological aspects, the influence of other factors related to socio-anthropological impressions and expressions toward not performing prenatal care by some pregnant women should be taken into account. For this, it is necessary to understand the meanings and social representations of pregnancy and the realization or not of the prenatal care. In this sense, the review study performed by Silva et $\mathrm{al}^{38}$ revealed that the significance of prenatal care involved sociocultural, family and emotional aspects. For some mothers of the mentioned study, ${ }^{38}$ gestation was not considered a happy or special moment in their lives, and the failure to perform the prenatal care was due to insecurity and fear of the unexpected and of punishment from the health professionals, and that made these women view prenatal care negatively. The importance of the caregivers' approach, integrating the family and considering the necessities of the women as a subject, their difficulties, expectations and sentiments in relation to the pregnancy. ${ }^{38}$

In the present study, the higher the parity, the higher the chance of developing anemia $(\mathrm{OR}=2.27)$. Results obtained from other investigations ${ }^{28,34}$ demonstrated that the prevalence of anemia in women increased with subsequent gestations due to the depletion of iron. It is valid to comment that the occurrence of anemia due to the depletion of the organic iron reserves can also be linked to a lower interval between pregnancies and to social and economic conditions, which determine the inadequate quality and quantity of food and FI, and to the despoliations caused by intestinal parasitosis, which are more frequent among pregnant women living in households with precarious sanitation. ${ }^{28}$

The lack to perform the medicinal supplementation of iron was another factor also related to prenatal care presented as a risk factor for anemia among the pregnant women in this study; it increased the chances of developing anemia to $145 \%(O R=2.45)$ among women who underwent the supplementation compared with those who did not. Results from other studies ${ }^{39,40}$ corroborate this finding. According to the study performed by Wendt et $\mathrm{al}^{39}$ with pregnant women from India, the authors identified chances $37 \%(\mathrm{OR}=1.37$ ) greater of developing anemia among pregnant women who did not undergo iron supplementation. In another investigation, conducted by Ononge et $\mathrm{al}^{40}$ with pregnant women from Uganda the chance of developing anemia rose to $66 \%(\mathrm{OR}=1.66)$. The results of the clinical 
trial by Rivot et $\mathrm{al}^{41}$ involving pregnant Spanish women did not show the effects of iron supplementation in the reduction of anemia during pregnancy. In Brazil, a clinical trial ${ }^{42}$ performed in the city of Recife, with the aim of evaluating the effectiveness of therapeutic regimens using ferrous sulfate in pregnant women with anemia, revealed that daily treatment was efficient in improving the serum concentrations of hemoglobin and ferritin.

Even if some degree of dissension is identified in the specific literature on the effectiveness of iron supplementation in pregnant women, well-conducted studies ${ }^{39-42}$ and meta-analyses ${ }^{43}$ have demonstrated significant effects of iron supplementation in improving the rates of anemia among pregnant women and some impacts on the reduction of: maternal mortality; the delay in intrauterine growth; low birth weight; and low iron reserves of the newborn.

In this context, it is important to emphasize that, in 2005 , the Brazilian Ministry of Health implemented the National Iron Supplementation Program with the purpose of promoting universal supplementation to children aged 6 to 18 months, pregnant women as of the 20th week, and women in the postpartum period, in order to control the prevalence of anemia in these groups. $^{44}$

In the plan for the development of policies for the control of anemia in Brazil, emphasis is given to the iron and folic acid medicinal supplementation program, and the program for the enrichment of wheat and corn flour with iron and folic acid, implemented in 2004. . $^{54}$

Although the results of the study of national scope by Fujimori et $a_{1}{ }^{5}$ which evaluated the impact of wheat and corn flour enriched with iron and folic acid in the hemoglobin serum concentrations of pregnant women, demonstrated a significant reduction in the prevalence of anemia from $25 \%$ to $20 \%$ in the total sample ( $n=12,119$ ), the prevalence is still high (in a moderate level) in the Northeast (29\%), Midwest (27.8\%) and North (25\%) regions of Brazil. These rates could be a reflection of the influence of socioeconomic, demographic and environmental factors that are distributed in a different manner among these regions of the country in relation to the South and Southeast regions, where prevalence rates were lower. ${ }^{5}$

It should be observed that one of the factors related to the effectiveness of this strategy is the consumption of enriched wheat and corn flour, namely by pregnant women. ${ }^{44}$ Thus, it is possible that FI situations, which are closely associated with socioeconomic (family income, the price of flour etc.), environmental (number of dwellers in the household) and behavioral aspects, compromise the access to and consumption of these foods, ${ }^{17}$ as well as of other adequate foods in terms of quality, quantity and sources of bioavailable iron, contributing, in this manner, toward the increase in the prevalence of anemia, especially due to iron deficiency, in pregnant women.

The importance of the development of strategies in nutritional education is also emphasized in the context of prenatal care, with the purpose of promoting healthy eating practices among the pregnant women, prioritizing the consumption of foods that are sources of iron and of other nutrients related to the synthesis of hemoglobin (vitamins A, B12, B9, among others).
From the methodological point of view, it should be considered that even with the statistical adjustment of the models of this study by different confounding factors, investigations with cross-sectional designs present some limitations. Among these is the limitation that hinders the fulfillment of the assumption of temporality, which is essentially important when it is not possible to determine the temporal extension of the variables of exposure on the outcome. Accordingly, the cross-sectional design does not enable the establishment of a relationship of cause and effect among the studied events, but identify associations among these. Nevertheless, a more robust method of analysis was used, the hierarchical analysis, which is based on a previously defined conceptual model that enabled a greater control of the confounding factors and the measurement of the breakdown of the total effect of their non-mediated components (or direct) in the relationships investigated.

\section{Conclusions}

The hierarchical analysis used in the present study enabled the identification of the determinants of anemia during pregnancy, collaborating to the identification of the confounding factors, and to the interpretation of the results in the light of socio-environmental, food safety and prenatal care aspects.

In this study, the chance of developing anemia among pregnant women was significantly higher than in other studies, mainly among women in situations of FI, not performing prenatal care, multipara and without iron supplementation.

We hope that these results will contribute to the development of integrated and intersectorial strategies for the control of anemia in pregnant women, considering, apart from the biological determinants, other factors, such as socio-environmental, food safety and prenatal care aspects, which can directly or indirectly interfere in the occurrence of anemia.

\section{Acknowledgments}

The authors would like to thank Fundação de Amparo à Pesquisa do Estado da Bahia (FAPESB) and Conselho Nacional de Desenvolvimento Científico e Tecnológico (CNPq) for their financial support. They would also like thank the women who agreed participate in this study.

Colaborators: F Demétrio conceived the study, participated in the data production, and was responsible for the preparation and critical review of the manuscript. CAS TelesSantos was responsible for the statistical analysis, interpretation of the results, and preparation of the manuscript. DB dos Santos was responsible for the planning, design, resource capture, production of data, research coordination, and contributed to the preparation of the manuscript.

\section{References}

1 Vieira BD, Parizzoto APAV. Alterações psicológicas decorrentes do período gravídico. Unoesc Ciênc ACBS 2013;4(01):79-90

2 Ferreira HdaS, Moura FA, Cabral Júnior CR. [Prevalence and factors associated with anemia in pregnant women from the semiarid region of Alagoas, Brazil]. Rev Bras Ginecol Obstet 2008;30(09): 445-451 Portuguese 
3 World Health Organization. Worldwide prevalence of anaemia 1993-2005: WHO global database on anaemia. Geneva: WHO; 2008

4 Bresani CC, Souza BAI, Batista Filho M, Figueiroa JN. Anemia e ferropenia em gestantes: dissensos de resultados de um estudo transversal. Rev Bras Saude Mater Infant 2007;7(Suppl 1):s15-s21

5 Fujimori E, Sato AP, Szarfarc SC, et al. Anemia in Brazilian pregnant women before and after flour fortification with iron. Rev Saude Publica 2011;45(06):1027-1035

6 Carvalho MC, Baracat ECE, Sgarbieri VC. Anemia ferropriva e anemia de doença crônica: distúrbios do metabolismo de ferro. Segur Aliment Nutr. 2006;13(02):54-63

7 Ikeanyi EM, Ibrahim AI. Does antenatal care attendance prevent anemia in pregnancy at term? Niger J Clin Pract 2015;18(03):323-327

8 Fischer NC, Shamah-Levy T, Mundo-Rosas V, Méndez-GómezHumarán I, Pérez-Escamilla R. Household food insecurity is associated with anemia in adult Mexican women of reproductive age. J Nutr 2014;144(12):2066-2072

9 Teles-Santos CAS. Modelagem multinível: uma abordagem aplicável em contextos de estudos longitudinais e de agregados. Feira de Santana: UEFS Editora; 2013

10 Victora CG, Huttly SR, Fuchs SC, Olinto MT. The role of conceptual frameworks in epidemiological analysis: a hierarchical approach. Int J Epidemiol 1997;26(01):224-227

11 Martins IS, de Alvarenga AT, de Siqueira AA, Szarfarc SC, de Lima FD. Biological and social determinants of disease: a study of iron deficiency anemia. Rev Saude Publica 1987;21(02):73-89

12 Bickel G, Nord M, Price C, Hamilton W, Cook J. Guide to measuring household food security revised. Alexandria: USDA; 2000

13 Instituto Brasileiro de Geografia e Estatística [Internet]. Censo 2010: Bahia: Santo Antonio de Jesus: infográficos: dados gerais do município. 2010 [cited 2015 Jan 14]. Available from: http://cidades.ibge. gov.br/painel/painel.php?lang=\&codmun $=292870 \&$ search $=$ bahia $\mid$ santo-antonio-de-jesus|infograficos:-dados-gerais-do-municipio

14 Genser B, Strina A, Teles CA, Prado MS, Barreto ML. Risk factors for childhood diarrhea incidence: dynamic analysis of a longitudinal study. Epidemiology 2006;17(06):658-667

15 Lohman TG, Roche AF, Martorell R. Anthropometric standardization reference manual. Champaign: Human Kinetics; 1988

16 National Academy of Science. Institute of Medicine. Weight gain during pregnancy: reexamining the guidelines: report brief. Washington (DC): National Academies Press; 2009

17 Santos CA, Strina A, Amorim LD, et al. Individual and contextual determinants of the duration of diarrhoeal episodes in preschool children: a longitudinal study in an urban setting. Epidemiol Infect 2012;140(04):689-696

18 Demétrio F. Elas têm fome de quê? (In)segurança alimentar e condições de saúde e nutrição de mulheres na fase gestacional [thesis]. Salvador: Universidade Federal da Bahia; 2015

19 Twisk JWR. Applied longitudinal data analysis for epidemiology: a practical guide. 2nd ed. Cambridge: Cambridge University Press; 2003

20 Akaike H. Information theory as an extension of the maximum likelihood principle. In: Proceedings of the 2nd International Symposium on Informational Theory; 1973; Budapest, Hungary. Budapest: Akadêmia Kiadó; 1973. p. 267-281

21 Miglioli TC, Brito AM, Lira PIC, Figueroa JN, Batista Filho M. Mother-child anemia in the State of Pernambuco, Brazil. Cad Saude Publica 2010;26(09):1807-1820

22 Rocha DS, Netto MP, Priore SE, Lima NMM, Rosado LEFPL, Franceschini SCC. Estado nutricional e anemia ferropriva em gestantes: relação com o peso da criança ao nascer. Rev Nutr 2005;18(04):481-489

23 Abriha A, Yesuf ME, Wassie MM. Prevalence and associated factors of anemia among pregnant women of Mekelle town: a cross sectional study. BMC Res Notes 2014;7:888

24 Khader A, Madi H, Riccardo F, Sabatinelli G. Anaemia among pregnant Palestinian women in the Occupied Palestinian Territory. Public Health Nutr 2009;12(12):2416-2420
25 Murillo OL, Zea MP, Pradilla A. Situación nutricional de la gestante y su recién nacido en Cali, 2008. Rev Salud Publica (Bogota) 2011; 13(04):585-596

26 Côrtes MH, Vasconcelos IAL, Coitinho DC. Prevalência de anemia ferropriva em gestantes brasileiras: uma revisão dos últimos 40 anos. Rev Nutr 2009;22(03):409-418

27 Park CY, Eicher-Miller HA. Iron deficiency is associated with food insecurity in pregnant females in the United States: National Health and Nutrition Examination Survey 1999-2010. J Acad Nutr Diet 2014;114(12):1967-1973

28 Fujimori E, Sato APS, Araújo CRMA, et al. Anemia em gestantes de municípios das regiões Sul e Centro-Oeste do Brasil. Rev Esc Enferm USP 2009;(43, Suppl 2):1204-1209

29 Schlindwein MM, Kassouf AL. Análise da influência de alguns fatores socioeconômicos e demográficos no consumo domiciliar de carnes no Brasil. Rev Econ Sociol Rural. 2006;44(03):549-572

30 Marano D, Gama SG, Domingues RM, de Souza Júnior PR. Prevalence and factors associated with nutritional deviations in women in the pre-pregnancy phase in two municipalities of the State of Rio de Janeiro, Brazil. Rev Bras Epidemiol 2014;17(01):45-58

31 Lôbo IKV. Coorte de nascimento de João Pessoa: efeitos da insegurança alimentar na saúde materno-infantil [dissertation]. João Pessoa: Universidade Federal da Paraíba; 2014

32 Brasil. Ministério da Saúde. Pesquisa Nacional de Demografia e Saúde da Criança e da Mulher - PNDS 2006: dimensões do processo reprodutivo e da saúde da criança. Brasília (DF): Ministério da Saúde; 2009

33 Instituto Brasileiro de Geografia e Estatística. Pesquisa Nacional por Amostra de Domicílios (PNAD): segurança alimentar 2013. Rio de Janeiro: IBGE; 2014

34 Guerra EM, Barretto OCO, Vaz AJ, Silveira MB. The prevalence of anemia in pregnant women in their first visit to health centers of a metropolitan area, Brazil. Rev Saude Publica 1990;24(05):380-386

35 Rezk M, Marawan H, Dawood R, Masood A, Abo-Elnasr M. Prevalence and risk factors of iron-deficiency anaemia among pregnant women in rural districts of Menoufia governorate, Egypt. J Obstet Gynaecol 2015;35(07):663-666

36 Szarfarc SC, de Siqueira AA, Martins IS, Tanaka ACD. Comparative study of biochemical indicators of iron concentration, in 2 population of pregnant women, with and without prenatal care. Rev Saude Publica 1982;16(01):1-6

37 Rasia ICRB, Albernaz E. Atenção pré-natal na cidade de Pelotas, Rio Grande do Sul, Brasil. Rev Bras Saude Mater Infant 2008;8(04): 401-410

38 Silva CO, Santos JLG, Pestana AL, Bernardi MC, Erdmann AL. Significados e expectativas de gestantes em relação ao pré-natal na atenção básica: revisão integrativa. Saúde Transf Soc. 2013;3(04):98-104

39 Wendt A, Stephenson R, Young M, et al. Individual and facilitylevel determinants of iron and folic acid receipt and adequate consumption among pregnant women in rural Bihar, India. PLoS One 2015;10(03):e0120404

40 Ononge S, Campbell O, Mirembe F. Haemoglobin status and predictors of anaemia among pregnant women in Mpigi, Uganda. BMC Res Notes 2014;7:712

41 Ribot B, Aranda N, Arija V. Early of late supplementation: similar evolution of the iron status during pregnancy. Nutr Hosp 2012; 27(01):219-226

42 de Souza AI, Batista Filho M, Ferreira LOC, Figueirôa JN. The effectiveness of three regimens using ferrous sulfate to treat anemia in pregnant women. Rev Panam Salud Publica 2004;15(05):313-319

43 Haider BA, Olofin I, Wang M, Spiegelman D, Ezzati M, Fawzi WW; Nutrition Impact Model Study Group (anaemia). Anaemia, prenatal iron use, and risk of adverse pregnancy outcomes: systematic review and meta-analysis. BMJ 2013;346:f3443

44 Szarfarc SC. Políticas públicas para o controle da anemia ferropriva. Rev Bras Hematol Hemoter 2010;32(Suppl 2):2-7 